journal homepage: https://www.artuklu.edu.tr/aijhs
Antuklu International Journal of Health Sciences

Derleme / Review

\title{
Hedonik Açlık
}

\section{Hedonic Hunger}

\author{
Sedat Coşkunsu $\mathrm{a}^{\mathrm{a}^{*}}$ \\ a Mardin Artuklu Üniversitesi, Sağlık Bilimler Fakültesi, Beslenme ve Diyetetik Bölümü, ORCID: https://orcid.org/0000-0002-9667-7854 \\ "İletişimden sorumlu yazar, E-mail: sedatcoskunsu@artuklu.edu.tr
}

\section{ARTICLE INFO}

\section{Article History:}

Received 06.07.2021

Received in revised form 17.08.2021

Accepted 24.08.2021

Keywords:

Food reward

Hedonic hunger

Obesity

Palatable

\begin{abstract}
Nowadays, an increasing proportion of food intake appears not to be related to only energy deprivation but also to getting pleasure from food. Nutrients sensory properties such as taste, image and smell are the most important criteria in the selection of nutrients. Palatable nutrients have an appetizing feature by stimulating dopamine, opioid and cannabinoid receptors in brain reward centers. Physiologically, hunger resulting from energy deprivation is defined as homeostatic hunger. The situation of getting pleasure from the consumption of delicious food without energy deprivation is defined as hedonic hunger. By eating delicious food, hedonic signals extend over homeostatic signals and increase consumption. Hedonic hunger leads to consumption even though the body does not need it. Consuming the most favourite food although being satiated after a meal is shown as an example of hedonic hunger. Feeding for pleasure or hedonic hunger potentially contributes to the rapid development of obesity worldwide.
\end{abstract}

(C) 2021 Mardin Artuklu University. All rights reserved.

\section{MAKALE BILLGILERI}

Makale Geçmişi:

Geliş Tarihi: 06.07.2021

Revizyon Tarihi: 17.08.202

Kabul Tarihi: 24.08.2021

\section{Anahtar Kelimeler}

Besin ödülü

Hedonik açlık

Obezite

Lezzet

\section{ÖZET}

Günümüzde besin alımındaki artış, yalnızca enerji eksikliği ile değil aynı zamanda besinden alınan zevk ile de ilişkili olduğudur. Besinlerin tadı, görüntüsü ve kokusu gibi duyusal özellikleri, besin seçiminde önemli kriterlerdir. Lezzetl besinler, beyin ödül merkezlerinde dopamin, opioid ve kanabinoid reseptörlerini uyararak iştahı artırmaktadır. Fizyolojik olarak, enerji depolarının tükenmesiyle oluşan açlık, homeostatik açlık olarak ifade edilmektedir. Hedonik açlık ise, yüksek derecede lezzetli yiyeceklerin varlığında bir enerji açığı olmaksızın zevk için yiyecek tüketimi olarak tanımlanmaktadır. Lezzetli besin alımı ile hedonik sinyaller homeostatik sinyallerin önüne geçerek tüketimi arttırmaktadır. Hedonik açlık, vücudun ihtiyacı olmasa da tüketime neden olur. Tok olunmasına rağmen sevilen bir besini tüketmek hedonik açlık için bir örnek olarak gösterilebilir. Zevk için beslenme veya hedonik açlık, dünya çapında obezitenin hızla gelișmesine katkıda bulunmaktadır.

(C) 2021 Mardin Artuklu Üniversitesi. Tüm hakları saklıdır.

\section{Giriş}

Günümüzde, dünya genelinde 600 milyon obez dahil 2,1 milyar kişi şişman bulunmaktadır. Birçok şişman birey normal ağırlığa gelmek için çabalamakta ancak kaybedilen ağılık uzun süre korunamamaktadır. Hafif şişman ve obezitenin yüksek prevalansı ve ağırlık kaybının zorluğu, ucuz ve elde edilmesi kolay, yüksek enerjili ve lezzetli besinlerin yaygın olduğu “obezojenik" bir ortamda yaşıyor olmamızdan kaynaklanmaktadır (1). Ortamda bulunan besin çeşitliliği ile ilişkili ipuçlarına maruz kalma (örneğin, besinleri görme, kokusunu alma, restoranlar gibi besin ile ilgili yerler vb.) psikolojik ve fizyolojik yanıtlardan oluşan besin ipuçlarını ortaya çıkarır. $\mathrm{Bu}$ besin ipuçları tarafından tetiklenen yanıtlar, aşırı beslenme dürtüsüne neden olur (2).
Homeostatik açlık, fizyolojik olarak vücudun enerji ihtiyacını gidermek için yeterli miktarda besin alımıyla gerçekleşir. Hedonik açlık ise, fizyolojik olarak bir enerji ihtiyaç olmaksızın besin arzusunun hayal edilmesi ve besinden alınan zevk beklentisi dürtüleriyle ortaya çıkan iştah durumu olarak ifade edilmektedir. Lezzetli besinlerin tüketimiyle hedonik sinyaller homeostatik sinyallerin önüne geçerek aşırı beslenmeyi arttırmaktadır. Böylece lezzetli besinler ile artan besin tüketimi obeziteye neden olmaktadır (3). Tat ve koku besinlerin tüketimi konusunda önemli bir gösterge olduğu için besin alımı ile doğrudan ilişkilidir. Lezzet ve açlık arasındaki etkileşime ek olarak algılanan haz ve buna karşılık besinlere verilen yanıt da besinlerin seçimini etkileyerek dolaylı olarak iștah kontrolünü 
düzenleyebilmektedir (4). Beğenme (liking), besinin tadı ile ilişkili haz ve hoşlanmayı yansıtmaktadır. İsteme (wanting) ise içsel olarak oluşan beslenme dürtüsü ve teşvik edici motivasyonu yansıtmaktadır. Bunların sonucu oluşan yüksek hedonik yanıt, ağırlık artışında önemli rol oynamaktadır (5). Günümüzde artan obezite prevalansında, önemli ölçüde aşırı beslenme ve hareketsiz yaşam tarzı neden olmaktadır. Besinlerin daha lezzetli olmasını sağlayan şeker ve yağ oranları aşırı beslenmenin ortaya çıkmasında önemli rol oynamaktadır. Lezzetli olan ve yükssek haz sağlayan besinlerin obeziteye katkı sağladığı belirtilmektedir (6). $\mathrm{Bu}$ yüzden lezzetli besinlerin çok miktarda sunulduğu ortamlar obezitenin gelişimine neden olmaktadır (7). Bu derlemenin amac1 hedonik açlığın etki mekanizmalarını ve obezite ile ilişkisini değerlendirmektir.

\subsection{Hedonik Açlık}

Günümüzde insanlarda yeme davranışının çoğunlukla fizyolojik bir ihtiyaca bağlı olmadan, besin ile ilgili çevresel tetikleyicilere verilen tepki tarafindan yönlendirildiği bilinmektedir. Besinleri görme ya da koklama, yemek yiyen insanların görülmesi ve yapılan reklamlar gibi tetikleyiciler, aç olmadığımız halde beslenmeye teşvik etmektedir. Fizyolojik olarak enerji depolarının tükenmesi sonucu oluşan açlık durumu homeostatik açlık olarak tanımlanırken, enerji ihtiyacı olmaksızın, lezzetli besinlerin tüketiminden sağlanan keyif amacıyla besin alımı durumu ise hedonik açlık olarak ifade edilmektedir (3). Fizyolojik sürecin yanı sıra sosyal bir aktivite olan beslenme, açlık olmadan psikolojik bir dürtü olarak ortaya çıkabilmektedir. Fiziksel açlık hissedilmeden bazı nedenlerden dolayı beslenme bir davranış olarak gözükmektedir. Beslenmenin bu hedonistik yanı kortikolimbik sinir ağ (ventral tegmantal alan, nukleus akkumbens, orbito frontal korteks ve amigdaladan oluşmakta) ve besin alımının motivasyonel, duygusal gibi psikolojik etkileri tarafından düzenlenmektedir (8).

Hedonik açlığı ortaya çıkaran iki durum vardır. Birincisi, enerji açığının olmadığı durum, ikincisi ise ortamda yüksek oranda çeşitli lezzetli besin tetikleyicilerin bulunmasıdır. Hedonik açlı̆g tetikleyebilecek son derece lezzetli besin uyaranlarının bulunmasıyla ortaya gizli potansiyeller çıkmaktadır. Bunlar; besin uyaranlarının teşvik edicisi "isteme" ve besinin tadı ile ilişkili "beğenme"dir ya da her ikisidir (9). Zevk deneyimini yansıtan "beğenme" ve teşvik motivasyonunu yansıtan "isteme" durumu nörobiyolojik sistemde farklı nörotransmitterlerden etkilenmektedir. "Beğenme" süreçlerine ve GABAerjik ve opioderjik yolaklar aracılık ederken, "isteme" süreçlerine mezolimbik dopaminerjik yolaklar aracılık etmektedir (10).

Ortamda bulunan besin çeşitliliği ile ilişkili ipuçlarına çok miktarda maruz kalınmaktadır. Örneğin, besinleri görme, kokusunu alma, restoranlar gibi besin ile ilgili yerler, psikolojik ve fizyolojik yanıtlardan oluşan besin ipuçlarını ortaya çıkarır. $\mathrm{Bu}$ besin ipuçları tarafından tetiklenen yanıtlar, aşırı beslenme dürtüsüne neden olur. Bu durum duyarlılığı yüksek hafif şişman ve obez bireylerde daha fazla bir şekilde görülmektedir $(2,11)$. Bireylerin homeostatik açlıktan ziyade hedonik açlıktan daha fazla etkilendiği ve bu nedenle ağırlık artışı olduğu ileri sürülmektedir (11). Ayrıca besin uyaranlarına karşı olan duyarlılı̆̆ın, metabolik açlığın olmadığı durumlarda daha fazla besin tüketimi ile ilişkili olduğu tespit edilmiş. Artan besin ödül duyarlılığı hem aşırı yeme hem de ağırlık artışı durumunu ortaya çıkarmıştır (12).

Besin Gücü Ölçeği (BGÖ) hedonik açlık durumunun değerlendirilmesini ölçmede kullanılmaktadır. BGÖ günümüz dünyasının çok çeşitli lezzetli besin ortamlarının psikolojik etkisini değerlendirmek için geliştirilmiştir. Bununla birlikte lezzetli besinlerin bolca ve sürekli olarak mevcut olduğu ortamlarda iştah ile ilgili düşünce, duygu ve isteklerin oluşturduğu bireysel farklılıkların bir ölçüsüdür (13).

\subsection{Besin Ödülünün Nörobiyolojik Mekanizması}

Beyin ödül merkezi, haz ve motivasyon gibi ödüllendirme davranışlarına aracılık eden sinir yolaklarından oluşmaktadır. Mezolimbik ve mezokortikal sistem; ventral tegental alandan (VTA) başlayıp, nukleus akkumbens (NAc), hippokampus ve orbitofrotal kortekse (OFC) kadar uzanan bir yolaktır. Bu alanlardaki nöronların uyarımında dopaminerjik ve opioderjik yolaklar aktif rol oynamaktadır. Beynin ödül sistemi, bir organizmanın hayatta kalma şansını artıran davranışları arttırmak için vardır. Ödül, fizyolojik veya psikolojik bir ihtiyacı gidermek için davranışları teşvik eden iç ve dış uyaranlara nöral bir "cevap" olarak tanımlanmaktadır (14). Lezzetli besinlerin tadı ödül sistemini harekete geçirir. Homeostatik beslenme ve ödül devreleri birbiriyle çok iç içedir ve beslenme davranışını birbirine bağl1 olarak düzenler (15).

Beslenme sistemi pozitif bir enerji dengesine doğru meyillidir. Enerji gereksinimlerinin karşılanmasından sonra besinlerin tat nitelikleri yeme davranışını ortaya çıkartabilir (16). Bunun nedeni, homeostatik olmayan sinyallerin (hedonik sinyaller) homeostatik sinyallerden daha güçlü olması ve önüne geçerek geçersiz kılmasıdır (17). Bununla birlikte hedonik sistemler, 
lezzetli besinlerin mevcudiyetinde beslenme davranışının artışı yoluyla obezite prevalansında artışa neden olmaktadır $(18,19)$.

Dopaminerjik ve opioiderjik sistemler, besin alımını teşvik etmek için birbiriyle bağlantılı olarak çalışırlar. Dopaminerjik sistem, beklenti ve besin arama davranışını yaratırken, opioiderjik sistem de zevki harekete geçirir (10). Homeostatik beslenme döngüsü ve nörotransmitterlerin yanı sira periferik metabolik sinyallerin hepsi, özellikle mezolimbik dopaminerjik yolaklar olmak üzere ödül yollarıyla etkileşir $(15,20)$. Lateral hipotalamik alan hem ödül hem de homeostatik devrelerin entegrasyonu için anahtar bir alandır. Lateral hipotalamik alan, ödül arayan davranışları ve motivasyon devrelerinin düzenleyicileri olarak hareket etmenin yanı sıra uyarılma ve homeostatik beslenmede rol oynar $(21,22)$. Aynı zamanda ventral tegmental alanı ve nukleus akkumbens'i doğrudan modüle eder (23). Özellikle nöronlar içeren çeşitli nöronal alt tipler (oreksin ve melanin konsantrasyon hormonu), lateral hipotalamik alan'dan ödül devresine kadar uzanır ve dopamin salınımını değiştirdiği gösterilmiştir (24).

\subsection{Besin Ödülünde Dopaminin Rolü}

Beyin ödül merkezinde en önemli nörotransmitter dopamindir. Dopamin, özellikle orta beyindeki ventral tegmental alandan, nukleus akkumbense ve aynı zamanda prefrontal korteks, amigdala ve hipotalamusu içeren nöronal bir ağ üzerinden besin ödülü için birincil öneme sahiptir (25). Kemirgenlerde akkumbal dopamin salınımını ölçen çalışma, mezoakkumbal dopamin yollarının, şekerle ve mısır yağıyla yapılmış tatlılarla aktive olduğunu ortaya çıkarmıştır (26). Dopamin sistemi üzerindeki bu etkilerle tutarlı olarak bu besinler, bir besin ödülü için de motive davranışları sergilemektedir (27). $\mathrm{Bu}$ çalışmalarda, besin ödüllendirmesi için motive edilmiş davranışlar, bir besin ödülü kazanmak için hayvanların giderek daha fazla çabaladığı (örneğin bir manivela basmak suretiyle) edimsel koşullandırma deneyleri kullanılarak gösterilmiştir. Besine edimsel (koşullu) yanıt, dopamin sinyalini arttıran ilaçlarla (örneğin amfetamin) arttırılabilir ve bastırılmış dopamin sinyalizasyonu ile azaltılabilir (28).

Besin ödülünde mezolimbik dopaminerjik yolaklar kritik rol oynamaktadır. Lezzetli yiyecekler NAc'de dopamin (DA) salınımını uyarmakta ve beslenme motivasyonunu etkilemektedir. Besinin hedonik etkisine (ödül değeri) bağlı olarak beynin kortiko-limbik bölgelerinin aktifleşmesi ve NAc'de DA artışı gösterilmiştir. BKI'si yüksek bireylerde dopamin D2 reseptörleri düşük bulunmuştur. Obez bireylerin düşük dopamin seviyesini normal düzeye getirmek için aşırı beslenmeye giriştiği ileri sürülmektedir (29). Lezzetli besinleri tüketme motivasyonu beynin mezokortikolimbik alanlardaki DA aktifleşme düzeyine bağlı olarak düzenlenmektedir (30). Besin bağımlılı̆̆ olan bireylerde DA yetersizliği olabileceği ileri sürülmektedir (31). DA yetersizliği olan bireyler kendini keyiflendirme ve rahatlatmak için eksikliklerini telafi etme eğilimindedirler. DA yetersizliği olan bireyler, lezzetli besinleri aşırı miktarda tüketerek dopamin aktivasyonunu arttırmaya çalışırlar (29). Ödüle karşı hassasiyeti yüksek bireyler daha iştahlı oldukları için bu durum vücut ağırlık kazanımına neden olur (16). Ödüle duyarlılığı yüksek olan bireylerin besin tercihlerinin yüksek yağlı besinler ve tatlılar yönünde olduğu vurgulanmıştır (32). Ödüle olan duyarlılık aşırı beslenme ile pozitif ilişkilidir (30). İnsan çalışmalarında, dopamin reseptörlerini bloke eden ilaçlar, insanların bir ödüle verdikleri memnuniyet derecelerini tamamen azaltamayabilirler (33). Örneğin, nörogörüntüleme çalışmaları, obez insanların ödül merkezlerinde dopamin D2 reseptör bağlanmasının daha düşük seviyelerine sahip olduğunu göstermiştir. Dopamin zevke neden oluyorsa, dopamin reseptörlerinin azaltılması besinden aldıkları zevki azaltabilir. Azaltılmış zevkin, bu bireylerin normal bir zevki elde etmek için daha fazla yemelerine neden olduğu ileri sürülmüştür. Bundan dolayı aşırı beslenme, ödül yetersizliği hipotezi desteklemektedir (34). Birçok beyin bölgesi, lezzetli besin ile aktivite edilir (35). Zevkle harekete geçirilen beyin bölgeleri; ventral tegmental alan, nükleus akkumbens, amigdala, orbitofrontal korteks ve hipokampüstür $(35,36)$.

\subsection{Besin Ödülünde m-Opioid Sinyalin Rolü}

Opioid sistem, madde kullanımı ve besin ödülüne dahil olan nöral mekanizmalarda yer alır. Lezzetli besinlerin hızlı tüketimi, zevk duygularına aracılık eden endojen opioidlerin salınımını uyarır. Gerçekten de NAc'in opioid reseptör uyarımının, tatlı ve yüksek yağlı besinlerin alımını arttırdığı gösterilmiştir. Antagonistler kullanılarak nukleus akkumbens kabuğunda endojen m-opioidin baskılanmasının, dürtüde hem sükrozun hem de bir besin ödülünün teşvik edici değerini azalttığını bulmuşlardır. Bununla tutarlı olarak, yakın bir zamanda bir m-opioid reseptör agonistinin bir besin ödülü için motive edici davranışı arttırdığı bildirilmiştir. Beyin ödül devrelerinde yer alan m-opioid sistemi, beslenmenin hedonik deneyiminde önemli derecede etkilemektedir (37). Nukleus akkumbenste, m-opioid sisteminin "beğenme" için de önemli olup olmadığı araştırılmış. Selektif antagonistler kullanılarak nukleus akkumbens kabuğunda endojen m-opioidin baskılanmasının, besin ödülünün teșvik edici değerini (arzu) 
azalttığını bulmuşlardır. Bununla tutarlı olarak, bir m-opioid reseptör agonistinin de bir besin ödülü için motive edici davranışı arttırdığı bildirilmiştir (7).

\subsection{Besin Ödüllendirmesinde Endokannabinoidlerin Rolü}

Endokannabinoidler, temel olarak besin alımina iten motivasyonel süreçlere aracılık ettiğini, opioid peptid sistemleriyle etkileşimler yoluyla yeme sırasında yiyeceklerin hedonik değerlendirmesine önemli katkı sağlayabileceği ileri sürülmektedir. Endokannabinoid-opioid aktivitesi, besin özleminin, yemekten zevk alma beklentisinin ve yiyeceğin duyusal özelliklerinden elde edilen gerçek zevk deneyiminin temelini oluşturur (38). Enerji dengesi ve vücut ağırlığını kontrol eden hipotalamik nükleustaki nöronlarda ve besin isteğinin oluşmasına aracılık ettiğine inanılan mezolimbik sistemdeki nöronlarda bulunmaktadır. Endokanabinoid sistemin uyarılmasıyla, lezzetli bir besinin alımını hem NAc'te bulunan dopaminin hem de hipotalamustaki iştah açıcı bazı aracıların salınımına neden olmaktadır. Hayvanlar üzerinde yapılan çalışmada endokanabinoid sistemin aşırı aktifleşmesiyle aşırı besin alımı sonucu obezitenin oluşumuna neden olabilmektedir (39). Kannabinoid reseptörü, besin alımı, besin ödüllendirmesi ve iştah davranışı ile ilişkili alanlar da dahil olmak üzere beyinde yaygın olarak yer alır. Endokannabinoidlerin, hipotalamusta ve arka beynin yanı sıra nukleus akkumbens içerisindeki birçok çekirdekte, oreksijenik etkileri için önemli görünmektedir (40). Kannobinoid sinyallemesinin hem dopaminerjik hem de opioid mekanizmalarla etkileşimleri içeren besin ödülü için önemli olduğu görülmektedir (41).

\section{Sonuc}

Besin endüstrisi ve pazarlamanın gelişmesinin bir sonucu olarak besinlerin “ödüllendirici özellikleri” artırılmış. Enerjiden zengin, yağ, şeker ve katkı maddeleriyle doyurulmuş, düşük besin değerli ve kolay ulaşılabilir bu "aşırı lezzetli besinlerin" çok fazla tüketilmesine ve obeziteye neden olduğu ileri sürülmektedir. Beyin ödül sisteminin lezzet ve haz alma süreci ile olan ilişkisi bazı besin maddelerinin aşırı tüketilmesi ile sonuçlanmaktadır. Obezitenin anlaşılmasında vücudun besine olan "ihtiyaç" sonucu değil besine karşı oluşan "beğenme" ve "isteme" davranışları önemli rol oynamaktadır. $\mathrm{Bu}$ durum, hedonik yemenin homeostatik yemenin önüne geçerek aşırı beslenmeye neden olabilmektedir. Obezite, homeostatik beslenmeden daha çok hedonik beslenme ve besin ipuçlarına karşı aşırı duyarlılık sonucu ortaya çıkmaktadır. Aksi takdirde beslenme sadece homeostatik mekanizmaların kontrolünde olsaydı herkes ideal vücut ağırlığına sahip olurdu. Besinlerden sağlanan haz da tüketimi arttırmaktadır. $\mathrm{Bu}$ nedenle lezzetli besinlerin sunulduğu çevresel ortamlar ve lezzetli besinlerle beraber şekillenen beslenme tarzı hedonik açlığın ve obezitenin gelişmesine neden olmaktadır. Obezite ve aşırı beslenmenin tetikleyici olan çevresel besin ipuçlarına fazla maruziyetin azaltılması için hükümet yetkilileri tarafindan önlemle alınmalıdır.

Çıkar Çatışması: Çalışmada herhangi bir çıkar çatışması yoktur.

Finansal Destek: $\mathrm{Bu}$ makalede herhangi bir finansal destek alınmamıştır.

Etik Kurul Onayı: Derleme türünde yazılan bu makalede etik kurul onayına gerek yoktur.

\section{Kaynaklar}

1. King BM. The modern obesity epidemic, ancestral hunter-gatherers, and the sensory/reward control of food intake. Am Psychol. 2013;68(2):88.

2. Van Den Akker K, Schyns G, Jansen A. Altered appetitive conditioning in overweight and obese women. Behav Res Ther. 2017;99:78-88.

3. Lutter M, Nestler EJ. Homeostatic and hedonic signals interact in the regulation of food intake. J. Nutr. 2009;139(3):629-32.

4. Rissanen A, Hakala P, Lissner L, Mattlar C, Koskenvuo M, Rönnemaa T. Acquired preference especially for dietary fat and obesity: a study of weightdiscordant monozygotic twin pairs. Int J Obes. 2002;26(7):973.

5. Mela DJ. Eating for pleasure or just wanting to eat? Reconsidering sensory hedonic responses as a driver of obesity. Appetite. 2006;47(1):10-7.

6. Salbe AD, DelParigi A, Pratley RE, Drewnowski A, Tataranni PA. Taste preferences and body weight changes in an obesity-prone population. Am J Clin Nutr. 2004;79(3):372-8

7. Egecioglu E, Skibicka KP, Hansson C, Alvarez-Crespo M, Friberg PA, Jerlhag E, et al. Hedonic and incentive signals for body weight control. Rev Endocr and Metab Disord. 2011;12(3):141-51.

8. Van Buren DJ, Sinton MM. Psychological aspects of weight loss and weight maintenance. J Acad Nutr Diet. 2009;109(12):1994-6.

9. Lowe MR, Butryn ML. Hedonic hunger: a new dimension of appetite? Physiol Behav. 2007;91(4):432-9.

10. Berridge KC. 'Liking'and 'wanting'food rewards: brain substrates and roles in eating disorders. Physiol Behav. 2009;97(5):537-50

11. Stroebe W, Papies EK, Aarts H. From homeostatic to hedonic theories of eating: Self-regulatory failure in food-rich environments. Appl Psychol. 2008;57:172-93.

12. Lipsky L, Nansel T, Haynie D, Liu D, Eisenberg M, Simons-Morton B. Power of Food Scale in association with weight outcomes and dieting in a nationally representative cohort of US young adults. Appetite. 2016;105:385-91.

13. Cappelleri JC, Bushmakin AG, Gerber RA, Leidy NK, Sexton CC, Karlsson J, et al. Evaluating the Power of Food Scale in obese subjects and a general sample of individuals: development and measurement properties. Int J Obes. 2009;33(8):913.

14. Berridge KC. Food reward: brain substrates of wanting and liking. Neurosci Biobehav Rev. 1996;20(1):1-25. 
15. Münzberg H, Qualls-Creekmore E, Yu S, Morrison CD, Berthoud H-R Hedonics act in unison with the homeostatic system to unconsciously control body weight. Front Nutr. 2016;3:6.

16. Kenny PJ. Reward mechanisms in obesity: new insights and future directions. Neuron. 2011;69(4):664-79.

17. Alonso-Alonso M, Woods SC, Pelchat M, Grigson PS, Stice E, Farooqi S, et al. Food reward system: current perspectives and future research needs. Nutr Rev. 2015;73(5):296-307.

18. Berthoud H-R. The neurobiology of food intake in an obesogenic environment. Proc of Nutr Soc. 2012;71(4):478-87.

19. Stice E, Figlewicz DP, Gosnell BA, Levine AS, Pratt WE. The contribution of brain reward circuits to the obesity epidemic. Neurosci Biobehav Rev. 2013;37(9):2047-58.

20. Berthoud H-R. Metabolic and hedonic drives in the neural control of appetite: who is the boss? Curr Opin Neurobiol 2011;21(6):888-96.

21. Burt J, Alberto CO, Parsons MP, Hirasawa M. Local network regulation of orexin neurons in the lateral hypothalamus. Am J Physiol Regul Integr Comp Physiol. 2011;301(3):R572-R80.

22. Figlewicz DP, Bennett-Jay JL, Kittleson S, Sipols AJ, Zavosh A. Sucrose selfadministration and CNS activation in the rat. Am J Physiol Regul Integr Comp Physiol. 2011;300(4):R876-R84.

23. Gutierrez R, Lobo MK, Zhang F, de Lecea L. Neural integration of reward, arousal, and feeding: recruitment of VTA, lateral hypothalamus, and ventral striatal neurons. IUBMB life. 2011;63(10):824-30.

24. Ho C-Y, Berridge KC. An orexin hotspot in ventral pallidum amplifies hedonic 'liking'for sweetness. Neuropsychopharmacology. 2013;38(9):1655.

25. Berridge KC. The debate over dopamine's role in reward: the case for incentive salience. Psychopharmacology. 2007;191(3):391-431.

26. Rada P, Avena N, Hoebel B. Daily bingeing on sugar repeatedly releases dopamine in the accumbens shell. Neuroscience. 2005;134(3):737-44.

27. Wojnicki F, Babbs R, Corwin R. Reinforcing efficacy of fat, as assessed by progressive ratio responding, depends upon availability not amount consumed. Physiol Behav. 2010;100(4):316-21

28. Baldo BA, Kelley AE. Discrete neurochemical coding of distinguishable motivational processes: insights from nucleus accumbens control of feeding. Psychopharmacology. 2007;191(3):439-59.

29. Cota D, Tschöp MH, Horvath TL, Levine AS. Cannabinoids, opioids and eating behavior: the molecular face of hedonism? Brain Res Rev. 2006;51(1):85-107.

30. Davis C, Patte K, Levitan R, Reid C, Tweed S, Curtis C. From motivation to behaviour: a model of reward sensitivity, overeating, and food preferences in the risk profile for obesity. Appetite. 2007;48(1):12-9.

31. Davis C, Fox J. Sensitivity to reward and body mass index (BMI): evidence for a non-linear relationship. Appetite. 2008;50(1):43-9.

32. Lowe MR, Levine AS. Eating motives and the controversy over dieting: eating less than needed versus less than wanted. Obesity. 2005;13(5):797-806.

33. Leyton M. The neurobiology of desire: Dopamine and the regulation of mood and motivational states in humans. 2010.

34. Geiger B, Haburcak M, Avena N, Moyer M, Hoebel B, Pothos E. Deficits of mesolimbic dopamine neurotransmission in rat dietary obesity. Neuroscience. 2009;159(4):1193-9.

35. Smith K, Mahler S, Pecina S, Berridge K, Kringlebach M. Pleasures of the Brain. 2010

36. Aldridge JW, Berridge KC. Neural coding of pleasure:"rose-tinted glasses" of the ventral pallidum. Pleasures of the Brain. 2010:62-73.

37. Pecina S, Cagniard $\mathrm{B}$, Berridge $\mathrm{K}$, Aldridge J, Zhuang $\mathrm{X}$. P54 Hyperdopaminergic mutant mice have higher 'wanting'but not 'liking'for sweet rewards. Behav Pharm. 2004;15(5):A24.
38. Kirkham TC. Endocannabinoids and the non-homeostatic control of appetite. Behavioral Neurobiology of the Endocannabinoid System: Springer; 2009. p. 23153

39. Tüfekçi Alphan E, Y1lmaz N. The effect of endocannabinoid system on energy metabolism and obesity. 2007.

40. Verty AN, McGregor IS, Mallet PE. Paraventricular hypothalamic CB1 cannabinoid receptors are involved in the feeding stimulatory effects of 9tetrahydrocannabinol. Neuropharmacology. 2005;49(8):1101-9.

41. DiPatrizio NV, Simansky KJ. Activating parabrachial cannabinoid CB1 receptors selectively stimulates feeding of palatable foods in rats. $\mathrm{J}$ Neurosci. 2008;28(39):9702-9. 